\title{
UTILIZAÇÃO DE FILMES DE POLIETILENO DE BAIXA DENSIDADE (PEBD) PARA PROLONGAR A VIDA PÓS-COLHEITA DE MORANGOS, CV. OSO GRANDE
}

\author{
JOEL DONAZZOLO ${ }^{1}$ \\ MAURÍCIO HUNSCHE ${ }^{2}$ \\ AURI BRACKMANN ${ }^{3}$ \\ ALESSANDRO JAQUIEL WACLAWOVSKY ${ }^{4}$
}

\begin{abstract}
RESUMO - Desenvolveu-se um experimento com o objetivo de avaliar o efeito da atmosfera modificada (AM), utilizando filmes de polietileno de baixa densidade (PEBD), sobre a manutenção da qualidade de morangos (Fragaria ananassa L.), cv. Oso Grande, acondicionados em câmara frigorífica, a $0^{\circ} \mathrm{C}$, e em câmara de climatização, a $20^{\circ} \mathrm{C}$, simulando transporte/armazenamento refrigerado e o transporte/armazenamento convencional, sob altas temperaturas respectivamente. Os morangos foram acondicionados em bandejas plásticas com capacidade para 300 g, envoltas por filme de polivinil cloreto (PVC) esticável de $15 \mu \mathrm{m}$ de espessura. Os tratamentos constituíram-se do recobrimento de seis bandejas, alojadas em armações de madeira utilizadas comercialmente para morangos, com filmes de PEBD com 22 [T2] ou $45 \mu \mathrm{m}$ [T3] de espessura. No tratamento-controle [T1], não se utilizou filme de PEBD. Antes do fechamento dos filmes de PEBD, foi retirado o ar e, injetado $\mathrm{CO}_{2}$, até atingir pressão parcial aproximada de $15 \mathrm{kPa}$. Todos os tratamentos foram
\end{abstract}

expostos às temperaturas de 0 e $20^{\circ} \mathrm{C}$, e cada temperatura foi considerada um experimento independente. $\mathrm{O}$ delineamento experimental utilizado foi o de blocos ao acaso, com três repetições e a unidade experimental composta por seis bandejas com 17 frutas cada uma. As avaliações foram realizadas após sete dias para o experimento a $20^{\circ} \mathrm{C}$ e, após 14 dias (com mais três dias em temperatura de $20^{\circ} \mathrm{C}$ ), para o experimento a $0^{\circ} \mathrm{C}$. Conforme os resultados, as frutas armazenadas a $20^{\circ} \mathrm{C}$ e com filmes de PEBD apresentaram menor incidência de podridões, menor índice de cor vermelha e menor acidez titulável, e também maior firmeza de polpa, em comparação com o tratamento-controle (sem filme de PEBD). Porém, a pressão parcial de $\mathrm{CO}_{2}$ atingiu cerca de $30 \mathrm{kPa}$ no interior de algumas bandejas envoltas com o filme de $45 \mu \mathrm{m}$, ocasionando sabor alcoólico às frutas. No experimento a $0^{\circ} \mathrm{C}$, não foram verificadas diferenças significativas para as variáveis avaliadas, embora o uso do filme de PEBD tenha proporcionado qualidade superior.

TERMOS PARA INDEXAÇÃO: Armazenamento, atmosfera modificada, temperatura, $\mathrm{CO}_{2}$, qualidade.

\section{THE USE OF LOW DENSITY POL YETHYLENE PACKING TO PROLONG THE POSTHARVEST LIFE OF 'OSO GRANDE' STRAWBERRIES}

\begin{abstract}
The experiment was carried out with the aim to evaluate the effect of modified atmosphere, using low-density polyethylene packaging (FPBD), on the quality of 'Oso Grande' strawberries (Fragaria ananassa L.) stored at $0^{\circ} \mathrm{C}$ and $20^{\circ} \mathrm{C}$. Approximately $300 \mathrm{~g}$ of fruits were placed into trays covered with a $15 \mu \mathrm{m}$ PVC film, and 6 trays were involved with a
\end{abstract}

FPBD film with 22 [T2] or $45 \mu \mathrm{m}$ [T3] thickness and then placed into a commercial wood box. Control fruits [T1] were not involved with FPBD film. After removing air, $15 \mathrm{kPa} \mathrm{CO}_{2}$ was injected into the $\mathrm{FPBD}$ bags before closing. The experimental design was a completely randomized blocs, with 3 replicates, each composed by 6 trays with 17 fruits. The evaluations

1. Engenheiro Agrônomo, Mestre em Agronomia - Produção Vegetal. Emater/RS. donazzolo@bol.com.br

2. Engenheiro Agrônomo, Mestre em Agronomia - Produção Vegetal. mhunsche@ bol.com.br

3. Engenheiro Agrônomo, Dr., Professor do Departamento de Fitotecnia - UFSM. brackman@ @cr.ufsm.br

4. Engenheiro Agrônomo, aluno de Doutorado em Fisiologia Vegetal/PPGFV - UFV. Ds43702@ correio.ufv.br 
were done after exposing the fruits for 7 days at $20^{\circ} \mathrm{C}$, and 14 days at $0^{\circ} \mathrm{C}$ plus 3 days at $20^{\circ} \mathrm{C}$. Fruits stored at $20^{\circ} \mathrm{C}$ with FPBD films had lower rot incidence, less red color, lower titratable acidity and higher pulp firmness. However, high $\mathrm{CO}_{2}$ partial pressure accumulated in the $45 \mu \mathrm{m}$ coatings $(30 \mathrm{kPa})$, which caused alcoholic taste. The fruits stored at $0^{\circ} \mathrm{C}$ did not show any differences between the evaluated treatments, but fruits involved with FPBD generally showed better quality.

INDEX TERMS: Storage, modified atmosphere, temperature, $\mathrm{CO}_{2}$, quality.

\section{INTRODUÇÃO}

A cultura do morango desenvolveu-se muito nos últimos anos, aumentando consideravelmente sua oferta. Os produtores passaram a adotar modernas tecnologias e, com isso, melhoraram a produtividade e a qualidade do produto e, conseqüentemente, conquistaram novos mercados que, às vezes, estão situados a longas distâncias. Torna-se de fundamental importância, portanto, desenvolver técnicas que permitam o transporte e o armazenamento dos morangos por períodos maiores, uma vez que o morango possui alta perecibilidade, decorrente de sua elevada taxa respiratória e suscetibilidade ao desenvolvimento de agentes patogênicos (Rosen \& Kader, 1989). Em poucos dias, as perdas podem alcançar 20 a 40\% (Oliveira et al., 1979).

Para diminuir e retardar a ocorrência dessas perdas, podem ser utilizadas baixas temperaturas e/ou atmosfera controlada (AC). Porém, na prática, a AC é uma técnica inviável para o armazenamento e transporte de morangos, por causa da curta vida pós-colheita das frutas e dos altos custos dos equipamentos. Para contornar o problema da inviabilidade da AC, pode-se lançar mão do uso da atmosfera modificada (AM). No caso do morango, o principal objetivo dessa técnica é promover o aumento das pressões parciais de $\mathrm{CO}_{2}$, atuando diretamente no metabolismo das frutas e/ou na germinação e desenvolvimento de agentes patogênicos (Wells \& Cota, 1970).

Diversos estudos já foram realizados e comprovaram os efeitos benéficos do uso do $\mathrm{CO}_{2}$ sobre a conservação de morangos, principalmente sobre a redução na taxa de perda de firmeza de polpa (Smith \& Skog, 1992; Kawada \& Kitagawa, 1993; Larsen \& Watkins 1995; Brackmann et al., 1999; Brackmann et al., 2001) e na ocorrência de podridões (Wells \& Cota, 1970; Ertan et al., 1990; Guinebretière et al., 1991; Shamaila et al., 1992; Smith, 1992), causadas, principalmente, por fungos dos gêneros Botrytis, Penicillium, Phomopsis $e$ Rhizopus (Instituto de Tecnologia dos Alimentos, 1978). No entanto, o acúmulo de $\mathrm{CO}_{2}$ no interior das embalagens de AM depende da taxa respiratória e quantidade de frutas, bem como do tipo e espessura do filme, além da temperatura de armazenamento (Brackmann \& Donazzolo, 2000).

Ke et al. (1991) afirmam que morangos podem ser armazenados por 10 dias na temperatura de $0^{\circ} \mathrm{C}$ a $5^{\circ} \mathrm{C}$, numa combinação de gases de 0,25 a $1,0 \mathrm{kPa}$ de $\mathrm{O}_{2}$ e $20 \mathrm{kPa}$ de $\mathrm{CO}_{2}$, sem causar efeitos negativos ao sabor. Hardenburg et al. (1986) e Muñoz-Delgado (1982) sugerem o armazenamento de morangos na temperatura de $0^{\circ} \mathrm{C}$. De acordo com Larsen (1994), o uso de AM com filmes comerciais de $19 \mu \mathrm{m}$ de baixa permeabilidade, 19 $\mu \mathrm{m}$ de alta permeabilidade e $40 \mu \mathrm{m}$, concentraram 45 , 20, e $11 \mathrm{kPa}$ de $\mathrm{CO}_{2}$, respectivamente.

No entanto, dependendo da concentração e do tempo de exposição ao $\mathrm{CO}_{2}$, pode-se observar variações no metabolismo normal das frutas, como ocorrência de off-flavor (Couey \& Wells, 1970; Larsen \& Watkins, 1995; Zhang \& Watkins, 1997), perda de aroma (Feng et al., 1993), aumento das concentrações de acetaldeído, etanol e etil acetato, em decorrência da respiração anaeróbica (Ke et al., 1993), além de alterações na coloração das frutas (Holcroft et al., 1997; Kader, 1997).

No presente trabalho, objetivou-se avaliar o efeito da AM, utilizando filmes de polietileno de baixa densidade (PEBD), sobre a manutenção da qualidade de morangos, cv. Oso Grande, acondicionados em câmara frigorífica, a $0^{\circ} \mathrm{C}$, e em câmara de climatização, a $20^{\circ} \mathrm{C}$, simulando o transporte/armazenamento refrigerado e o transporte/armazenamento convencional sob altas temperaturas, respectivamente.

\section{MATERIAL E MÉTODOS}

O experimento foi conduzido no Núcleo de Pesquisa em Pós-colheita (NPP) do Departamento de Fitotecnia da Universidade Federal de Santa Maria (UFSM), com frutas provenientes de cultivos comerciais do município de Farroupilha-RS. Aproximadamente 10 h após a colheita, as frutas foram selecionadas, eliminando-se aquelas fora do padrão do ponto de maturação ou com ferimentos, sendo, em seguida, separadas em três classes de tamanho.

Os morangos foram acondicionados em bandejas plásticas, envoltas por filme de PVC esticável de 15 $\mu \mathrm{m}$, totalizando $\pm 300 \mathrm{~g}$. Os tratamentos constituíram-se

Ciênc. agrotec., Lavras. V.27, n.1, p.165-172, jan./fev., 2003 
do recobrimento de seis bandejas, alojadas em armações de madeira utilizadas comercialmente para morangos, com filmes de polietileno de baixa densidade (PEBD) de 22 [T2] ou 45 $\mu \mathrm{m}$ [T3] de espessura. No tratamento-controle [T1], não se utilizou filme de PEBD. Os tratamentos foram dispostos nas temperaturas de $0 \mathrm{e}$ $20^{\circ} \mathrm{C}$, e cada temperatura foi considerada um experimento independente. $\mathrm{O}$ delineamento experimental utilizado foi o de blocos ao acaso (classes de tamanho), com três repetições e a unidade experimental composta por seis bandejas com 17 frutas cada uma, em ambos os experimentos.

Antes do fechamento dos filmes de PEBD, retirou-se o ar da embalagem injetou-se, aproximadamente, $15 \mathrm{kPa}$ de $\mathrm{CO}_{2}$ proveniente de um cilindro de alta pressão. $\mathrm{O}$ monitoramento das pressões parciais de $\mathrm{O}_{2}$ e $\mathrm{CO}_{2}$ foi realizado mediante análise diária, com o auxílio de um analisador eletrônico de fluxo contínuo, marca Agridatalog. Foram analisadas as atmosferas do interior das bandejas e da embalagem com filme de PEBD.

As avaliações foram realizadas após sete dias para o experimento a $20^{\circ} \mathrm{C}$ e após 14 dias (com mais três dias em temperatura de $20^{\circ} \mathrm{C}$ ) para o experimento a $0^{\circ} \mathrm{C}$. As variáveis avaliadas foram: $a$ ) firmeza de polpa: determinada com uso de penetrômetro manual de alta precisão com leitura de 0 a $14 \mathrm{~N}$, munido de uma ponteira de 7,9 mm, perfurando-se cada fruta em dois lados opostos; $b$ ) acidez total titulável: determinada por titulação de $10 \mathrm{ml}$ de suco em $100 \mathrm{ml}$ de água destilada, com solução de $\mathrm{NaOH} 0,1 \mathrm{~N}$ até $\mathrm{pH} 8,1 ; c)$ teores de sólidos solúveis totais (SST): determinados por refratometria manual, com posterior correção do efeito da temperatura; $d$ ) escurecimento das sépalas: avaliado utilizandose uma escala subjetiva de 1 a 3 , que considerava a relação da área escurecida e necrosada com a área total da superfície das sépalas, e os índices 1,2 e 3 representavam $<10 \%, 10$ a $40 \%$ e $>40 \%$ da área total das sépalas escurecidas e necrosadas, respectivamente; $e$ ) cor das frutas: avaliada com uma escala subjetiva de 1 a 3 , em que frutas classificadas como índice 1 apresentavam $<75 \%$ da epiderme com coloração vermelha, como índice 2 quando apresentavam de 75 a $95 \%$ e como índice 3 quando mais de $95 \%$ da área da epiderme estava vermelha; $f$ ) podridões: baseada na avaliação visual e expressa em percentual de frutas, sendo consideradas frutas podres aquelas que apresentavam sintomas típicos de ataque de patógenos. Nos itens $\boldsymbol{d}$ e $\boldsymbol{e}$, a média de cada amostra foi calculada multiplicando-se o número de frutas de cada índice pelo seu respectivo índice e dividindo-se a somatória desse valor pelo número total de frutas da amostra.
No momento da instalação do experimento, os morangos apresentavam as seguintes características: $10,36 \mathrm{~N}$ de firmeza de polpa; $6,93^{\circ} \mathrm{Brix}$ de sólidos solúveis totais (SST); 9,89 cmol. $\mathrm{L}^{-1}$ de acidez titulável e índice de cor de 1,7 .

Os resultados obtidos foram submetidos à análise de variância e análise de regressão para os efeitos do tratamento (espessura dos filmes de PEBD). A escolha das regressões foi a $5 \%$ de probabilidade de erro. Valores expressos em percentual foram transformados pela fórmula $\operatorname{arc} . \operatorname{sen} \sqrt{\mathrm{x} / 100}$ antes da análise da variância.

\section{RESULTADOS E DISCUSSÃO}

No experimento a $0^{\circ} \mathrm{C}$, a utilização de filmes de PEBD sobre as bandejas não influenciou o comportamento pós-colheita dos morangos (Tabela 1). Ao avaliar as condições da atmosfera que envolvia as frutas durante o período de armazenamento, verificou-se que a pressão parcial de $\mathrm{CO}_{2}$ no interior das embalagens com filmes de PEBD de 22 e $45 \mu \mathrm{m}$ decresceu continuamente após a injeção inicial desse gás (Figura 1A). No interior das bandejas cobertas com PVC (Figura 1B), as pressões parciais de $\mathrm{CO}_{2}$ ficaram abaixo de $1 \mathrm{kPa}$ no tratamento-controle (sem filme de PEBD). Já, com a utilização dos filmes de PEBD, houve acúmulo nos primeiros dias e um posterior decréscimo. $\mathrm{O} \mathrm{O}_{2}$ permaneceu sempre acima de $10 \mathrm{kPa}$, não exercendo, dessa maneira, efeito significativo sobre o metabolismo das frutas nessa temperatura.

Em nenhum momento, no experimento a $0^{\circ} \mathrm{C}$, as pressões parciais de $\mathrm{CO}_{2}$ foram suficientemente altas para reduzir o metabolismo das frutas a ponto de promover a manutenção da qualidade dos morangos, bem como para reduzir o desenvolvimento dos fungos. Em trabalhos experimentais, verificou-se que, para o $\mathrm{CO}_{2}$ ter efeito positivo na manutenção da qualidade das frutas, sua pressão parcial deve ser superior a $10 \mathrm{kPA}$ (Kawada \& Kitagawa, 1993). Brackmann et al. (2001), em estudos com atmosfera controlada, mostraram que 20 $\mathrm{kPa}$ de $\mathrm{CO}_{2}$ reduz a perda de firmeza de polpa e a ocorrência de podridões em morangos 'Oso Grande' armazenados por 20 dias a $0^{\circ} \mathrm{C}$.

Pelos resultados obtidos verifica-se que a quantidade de frutas, o tipo e a espessura dos filmes utilizados, a $0^{\circ} \mathrm{C}$, não permitiram a manutenção da pressão parcial inicial de $\mathrm{CO}_{2}$, ou até mesmo o acúmulo desse gás no interior das embalagens e das bandejas em níveis adequados. Deve-se, portanto, buscar a otimização das características dos filmes (tipo, espessura e permeabilidade) para o recobrimento das bandejas de morangos, 
bem como da pressão parcial inicial de $\mathrm{CO}_{2}$ a ser injetada na embalagem, a fim de obter uma atmosfera adequada ao redor das frutas para aumentar o período de conservação a $0^{\circ} \mathrm{C}$. Larsen \& Watkins (1995) verificaram que a combinação de $10 \mathrm{kPa} \mathrm{CO}$ com $2 \mathrm{kPa} \mathrm{O}$ proporcionou os melhores resultados na manutenção da qualidade quando do armazenamento em atmosfera controlada. Entretanto, quando essas pressões parciais foram obtidas com a modificação da atmosfera, a qualidade das frutas foi baixa, por causa do maior tempo necessário para atingir pressões parciais de $\mathrm{O}_{2}$ e $\mathrm{CO}_{2}$ que influenciassem o metabolismo.

TABELA 1 - Efeito da utilização de filmes de PEBD na qualidade pós-colheita de morangos 'Oso Grande', após 14 dias de armazenamento refrigerado a $0^{\circ} \mathrm{C}$ e mais três dias a $20^{\circ} \mathrm{C}$. Santa Maria, RS, 2000.

\begin{tabular}{|c|c|c|c|c|c|c|}
\hline Tratamento & $\begin{array}{l}\text { Firmeza de } \\
\text { Polpa (N) }\end{array}$ & $\begin{array}{c}\text { ATT } \\
\left(\mathrm{cmol}^{-1} \mathbf{L}^{-1}\right)\end{array}$ & $\begin{array}{ll}\text { Cor } & \\
\text { 3) } & \text { (1- }\end{array}$ & $\begin{array}{c}\text { Podridões } \\
(\%)\end{array}$ & $\begin{array}{l}\text { Escurec. de } \\
\text { Sépalas (1-3) }\end{array}$ & $\begin{array}{c}\text { SST } \\
\left({ }^{\circ} \text { Brix }\right)\end{array}$ \\
\hline Controle & $6,46^{\mathrm{ns}}$ & $9,35^{\text {ns }}$ & $2,57^{\mathrm{ns}}$ & $70,98^{\text {ns }}$ & $2,19^{\text {ns }}$ & $7,5^{\mathrm{ns}}$ \\
\hline $22 \mu \mathrm{m}$ & 8,17 & 8,60 & 2,44 & 50,00 & 1,81 & 7,6 \\
\hline $45 \mu \mathrm{m}$ & 8,70 & 8,53 & 2,43 & 50,00 & 1,98 & 7,5 \\
\hline MÉDIA & 7,77 & 8,82 & 2,48 & 56,99 & 1,99 & 7,54 \\
\hline $\mathrm{CV}(\%)$ & 13,57 & 3,42 & 2,65 & 11,17 & 9,76 & 2,99 \\
\hline
\end{tabular}

ATT - Acidez Total Titulável

ns - regressões não significativas em nenhum grau.

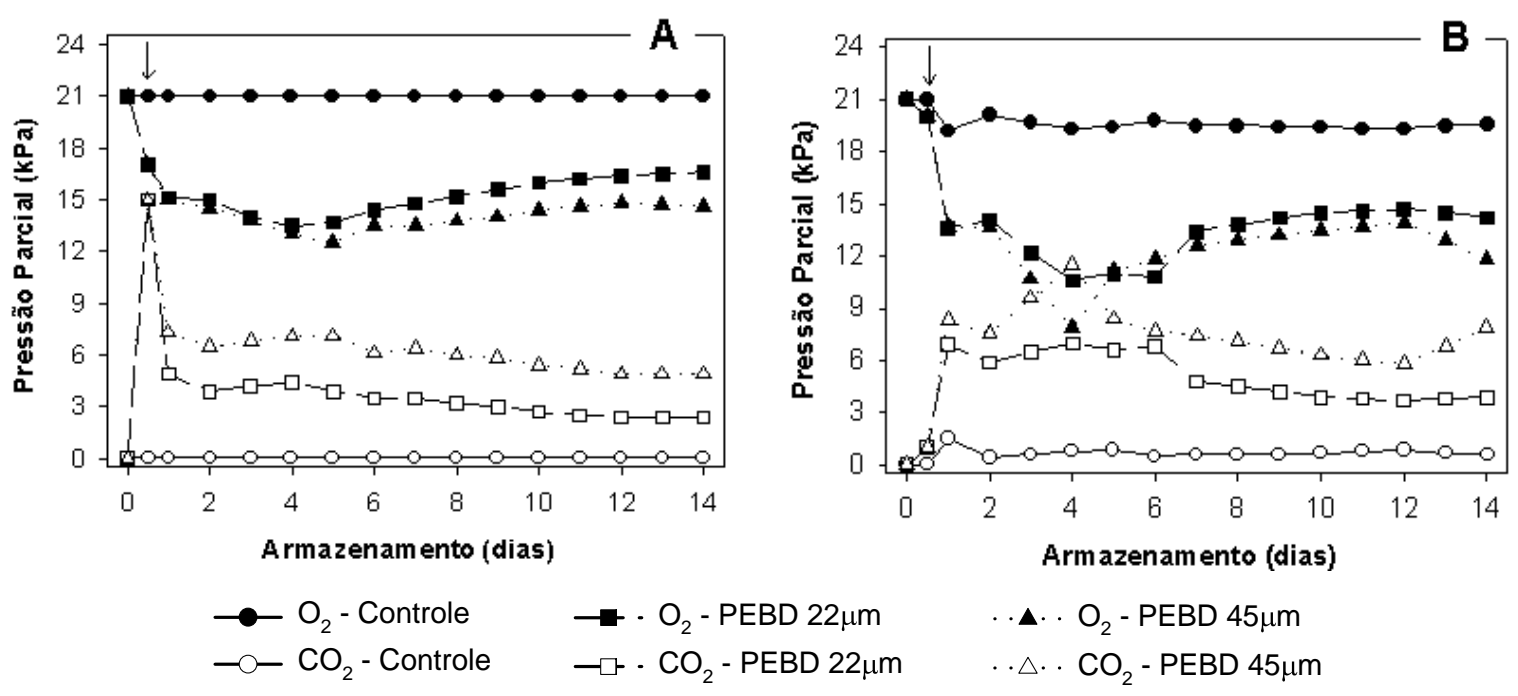

FIGURA 1 - Evolução das pressões parciais de $\mathrm{O}_{2}$ e $\mathrm{CO}_{2}$ no interior das embalagens de PEBD (A) e das bandejas (B) durante o armazenamento de morangos a $0^{\circ} \mathrm{C}$. Santa Maria, RS, 2000. Obs.: A seta indica o momento da injeção de $\mathrm{CO}_{2}$. 
Deve-se ressaltar, no entanto, que as frutas foram analisadas três dias após sua retirada das câmaras frigoríficas, período durante o qual permaneceram a $20^{\circ} \mathrm{C}$. A elevação de temperatura provocou uma rápida perda da qualidade das frutas e uma grande incidência de podridões (Tabela 1), pois, na retirada da câmara frigorífica, os morangos estavam, visualmente, em condições adequadas para consumo. Dessa maneira, pode-se dizer que utilização de baixa temperatura até o momento do consumo é imprescindível.
Com relação ao experimento conduzido na temperatura de $20^{\circ} \mathrm{C}$, verificou-se um efeito significativo e benéfico dos filmes de PEBD sobre a manutenção da firmeza de polpa sobre a evolução da cor vermelha e sobre a incidência de podridões (Tabela 2 e Figura 3). Esses resultados, possivelmente, são decorrentes do acúmulo de $\mathrm{CO}_{2}$ e da menor pressão parcial de $\mathrm{O}_{2}$, no interior das bandejas embaladas com os filmes de PEBD sobre o metabolismo das frutas (Figura 2).

TABELA 2 - Efeito da utilização de filmes de PEBD na qualidade pós-colheita de morangos cv. Oso Grande, após sete dias a $20^{\circ} \mathrm{C}$. Santa Maria, RS, 2000.

\begin{tabular}{|c|c|c|c|c|c|c|}
\hline Tratamento & $\begin{array}{l}\text { Firmeza de } \\
\text { Polpa (N) }\end{array}$ & $\underset{\left(\mathrm{cmol}^{\mathrm{ATT}} \mathbf{L}^{-1}\right)}{\mathrm{ATT}}$ & Cor (1-3) & $\begin{array}{c}\text { Podridões } \\
(\%)\end{array}$ & $\begin{array}{l}\text { Escurec. de } \\
\text { Sépalas (1-3) }\end{array}$ & $\begin{array}{c}\text { SST } \\
\left({ }^{\circ} \text { Brix }\right)\end{array}$ \\
\hline Controle & $5,25^{1}$ & $11,16^{1}$ & $2,92^{1}$ & $80,00^{1}$ & $2,62^{\mathrm{ns}}$ & $7,0^{\mathrm{ns}}$ \\
\hline $22 \mu \mathrm{m}$ & 6,37 & 8,21 & 2,70 & 30,00 & 2,70 & 7,1 \\
\hline $45 \mu \mathrm{m}$ & 7,07 & 7,91 & 2,36 & 17,66 & 2,76 & 7,2 \\
\hline MÉDIA & 6,23 & 9,09 & 2,66 & 42,55 & 2,70 & 7,1 \\
\hline $\mathrm{CV}(\%)$ & 9,41 & 5,21 & 3,74 & 3,08 & 6,41 & 4,61 \\
\hline
\end{tabular}

ATT - Acidez Total Titulável

\section{1 - regressão linear e/ou quadrática significativa a $5 \%$ de probabilidade de erro; ns - regressões não significativas em nenhum grau.}
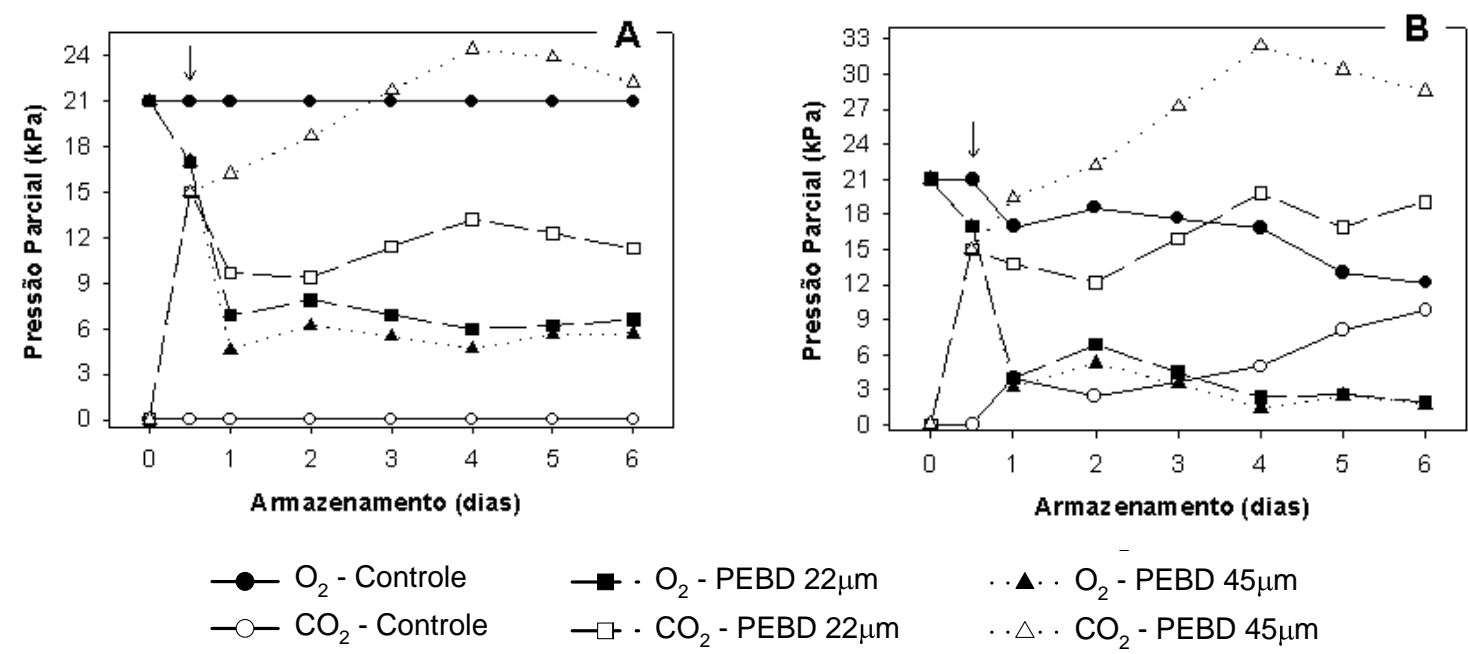

FIGURA 2 - Evolução das pressões parciais de $\mathrm{O}_{2}$ e $\mathrm{CO}_{2}$ no interior das embalagens de PEBD (A) e das bandejas (B) durante o armazenamento de morangos, cv. Oso Grande, a $20^{\circ} \mathrm{C}$. Santa Maria, RS, 2000. Obs.: A seta indica o momento da injeção de $\mathrm{CO}_{2}$. 

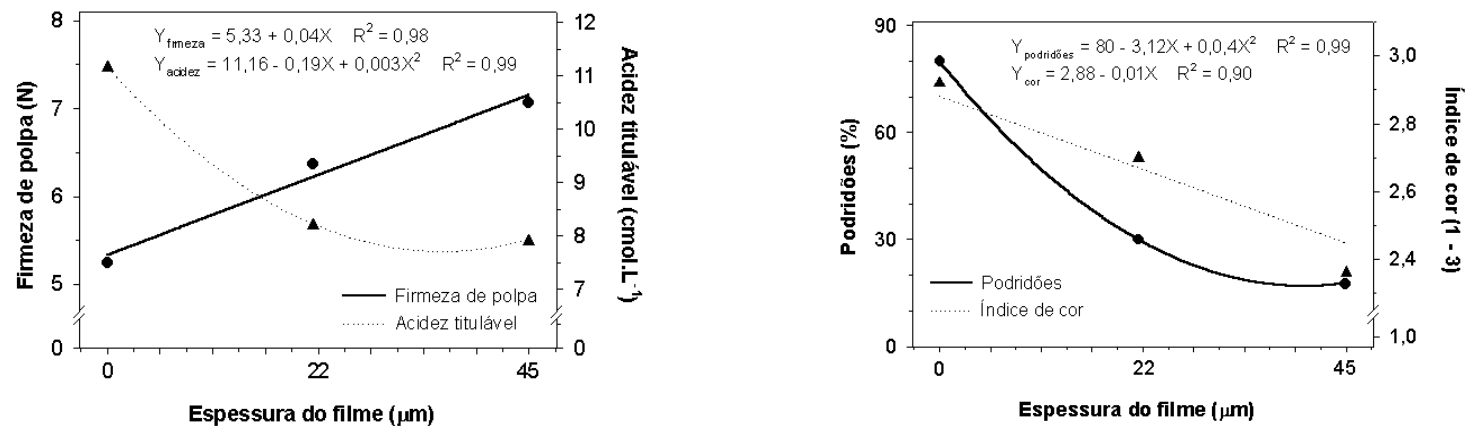

FIGURA 3 - Efeito da espessura das embalagens de PEBD sobre a qualidade de morangos, cv. Oso Grande, após o armazenamento a $20^{\circ} \mathrm{C}$. Santa Maria, RS, 2000.

Menor perda de firmeza de polpa com a utilização de elevadas pressões parciais de $\mathrm{CO}_{2}$ já foi relatada anteriormente (Kawada \& Kitagawa, 1993; Brackmann et al., 1999; Holcroft \& Kader, 1999; Brackmann et al., 2001). Em trabalhos desenvolvidos por Smith \& Skog (1992) e Watkins \& Zhang (1998), observou-se um aumento na firmeza de polpa dos morangos, e não simplesmente manutenção ou decréscimo na taxa desse processo durante o armazenamento.

O índice de cor, que representa a área superficial das frutas coberta por pigmentos vermelhos, apresentou resposta linear e negativa em função das espessuras de filmes plásticos testados (Figura 3). Esse índice significa para os consumidores o ponto de maturação para consumo e, portanto, quanto maior, mais madura a fruta. Brackmann et al. (2001) obtiveram resultados similares quando armazenaram morangos sob elevadas pressões parciais de $\mathrm{CO}_{2}$ a $20^{\circ} \mathrm{C}$, mas não constataram efeito do $\mathrm{CO}_{2}$ quando utilizaram a temperatura de $0^{\circ} \mathrm{C}$. Os morangos armazenados sob elevadas pressões parciais de $\mathrm{CO}_{2}$ têm menor síntese de antocianinas (Holcroft, 1997 et al.; Holcroft \& Kader, 1999), o que poderia justificar os resultados obtidos neste experimento.

As podridões foram drasticamente reduzidas com o aumento da espessura dos filmes de PEBD (Figura 3). Esse resultado é atribuído ao efeito fungistático do $\mathrm{CO}_{2}$ acumulado dentro das embalagens (Figura 2), o que já foi comprovado anteriormente (Ertan et al., 1990; Guinebretière et al., 1991; Shamaila et al., 1992; Smith, 1992; Brackmann et al., 1999, 2001). Segundo Wells \& Cota (1970), o crescimento de Botrytis cinerea e Rhizopus stolonifer em atmosfera com $20 \mathrm{kPa} \mathrm{CO}_{2}$ foi inibido em aproximadamente $50 \%$.
A acidez titulável foi reduzida com o aumento da espessura dos filmes de PEBD (Figura 3). Na maioria das frutas, isso indicaria maior atividade metabólica. Os efeitos do elevado teor de $\mathrm{CO}_{2}$ na atividade enzimática são, freqüentemente, descritos como decorrentes da redução do pH intracelular, em função da geração de ácido carbônico (Watkins \& Zhang, 1998). Entretanto, para o morango, isso parece não ser verdadeiro. Holcroft \& Kader (1999) observaram aumento de pH e decréscimo da acidez total titulável em morangos armazenados sob elevadas pressões parciais de $\mathrm{CO}_{2}$. Segundo os mesmos autores, a acidez titulável, por determinar apenas a quantidade de ácidos livres, não é um método preciso para a determinação dos ácidos totais, uma vez que os últimos englobam também os ácidos conjugados a açúcares (Ulrich, 1970). Brackmann et al. (2001) não verificaram efeito de diferentes pressões parciais de $\mathrm{CO}_{2}$, com uso de AC, sobre a acidez titulável de morangos.

Os teores de SST e o escurecimento das sépalas das frutas armazenadas a $20^{\circ} \mathrm{C}$ não foram afetados pelas condições atmosféricas obtidas com a utilização das embalagens de PEBD (Tabela 2). Em experimento desenvolvido com atmosfera controlada, Brackmann et al. (2001) constataram que as pressões parciais de $\mathrm{CO}_{2}$ exercem pequena influência sobre o conteúdo de SST.

Um dos aspectos negativos do armazenamento de morangos sob elevado teor de $\mathrm{CO}_{2}$ é o acúmulo de acetaldeído, etanol e etil acetato, decorrentes da respiração anaeróbica (Ke et al., 1993). No presente trabalho, verificou-se que, durante o armazenamento a $20^{\circ} \mathrm{C}$, a pressão parcial de $\mathrm{CO}_{2}$ atingiu níveis superiores a 25 $\mathrm{kPa}$ no filme de $45 \mu \mathrm{m}$, o que é considerado muito elevado. Em decorrência disso, os morangos, nas bandejas cobertas pelo filme de PEBD com $45 \mu \mathrm{m}$ de espessura e armazenados a $20^{\circ} \mathrm{C}$, apresentaram sabor alcoólico, sem 
condições de comercialização. Também as baixas pressões parciais de $\mathrm{O}_{2}$ (Figura 3 ) podem ter contribuído para a modificação do sabor, apesar de frutas armazenadas sob $1 \mathrm{kPa} \mathrm{O}_{2}$ apresentarem-se aceitáveis para o consumo (Couey \& Wells, 1970). A utilização de um filme constituído de um material diferente e/ou de menor espessura ou a injeção de menos $\mathrm{CO}_{2}$ no início do armazenamento podem propiciar melhores condições para o armazenamento de morangos, cv. Oso Grande, a $20^{\circ} \mathrm{C}$.

\section{CONCLUSÕES}

Com base nos resultados obtidos neste experimentos pode-se concluir que:

A utilização de filmes de PEBD de 22 ou $45 \mu \mathrm{m}$ de espessura para o armazenamento de morangos $\mathrm{cv}$. Oso Grande em atmosfera modificada, acondicionados em bandejas cobertas por filme de PVC de $15 \mu \mathrm{m}$, não proporcionou a manutenção da qualidade das frutas armazenadas por 14 dias a $0^{\circ} \mathrm{C}$ e mais três dias a $20^{\circ} \mathrm{C}$, por não modificar suficientemente a atmosfera.

Morangos cv. Oso Grande, acondicionados em bandejas armazenadas a $20^{\circ} \mathrm{C}$ e embaladas com filmes de PEBD de $45 \mu \mathrm{m}$, apresentaram maior firmeza de polpa, menor evolução da cor vermelha e menor perda por podridões; porém, apresentaram sabor alcoólico.

\section{REFERÊNCIAS BIBLIOGRÁFICAS}

BRACKMANN, A.; DONAZZOLO, J. Armazenagem de caqui. In: ENCONTRO NACIONAL SOBRE FRUTICULTURA DE CLIMA TEMPERADO, 3., 2000, Fraiburgo. Anais... Videira: EPAGRI, 2000. p. 99-102.

BRACKMANN, A.; HUNSCHE, M.; MAZARO, S. M. Efeito do alto $\mathrm{CO}_{2}$ e do armazenamento em atmosfera modificada sobre a qualidade pós-colheita de morangos (Fragaria ananassa L.) cv. Tangi. Científica Rural, Bagé, v. 4, n. 1, p. 58-63, 1999.

BRACKMANN, A.; HUNSCHE, M.; WACLAWOVSKY, A. J.; DONAZZOLO, J. Armazenamento de morangos cv. Oso Grande (Fragaria ananassa L.) sob elevadas pressões parciais de $\mathrm{CO}_{2}$. Revista Brasileira de Agrociência, Pelotas, v. 7, n. 1, 2001.

COUEY, H. M.; WELLS, J. M. Low oxygen or high carbon dioxide atmospheres to control postharvest decay of strawberries. Phytopathology, Saint Paul, v. 60, p. $47-49,1970$.
ERTAN, Ü.; ÖZELKÖK, S.; CELIKEL, F.; KEPENEK, K. The effects of precooling and increased atmospheric concentrations of $\mathrm{CO}_{2}$ on fruit quality and postharvest life of strawberries. Bahce, Yalova, v. 1-2, n. 19 , p. 59-76, 1990.

FENG, S.; GIANG, W. H.; YANG, D. Q.; CAO, J. S. "Baojiao" strawberry storage life influenced by the treatments of carbon dioxide and sulfur dioxide. Acta Agriculturae, Pekinensis, v. 3, n. 19, p. 53-57, 1993.

GUINEBRETIÈRE, M. H.; CHAMBROY, Y.; SOUTY, M. The effect of partial pressure of atmosphere carbon dioxide on microbiological quality of strawberries after harvesting. Montfavet, [S.1.], p. 351-360, 1991.

HARDENBURG, R. E.; WATADA, A. E.; WANG, C. $Y$. The commercial storage of fruits, vegetables and florist nursery stocks. [S.1.]: United States Department of Agriculture, 1986. 136 p. Agriculture Handbook n. 66 - revised.

HOLCROFT, D. M.; GIL, M. I.; KADER, A. A. Effect of carbon dioxide on anthocyanin biosynthesis during storage of fresh strawberry. In: INTERNATIONAL CONTROLLED ATMOSPHERE RESEARCH CONFERENCE, 3., 1997, Davis. Proceedings... Davis: [s.n.], 1997. p. 36.

HOLCROFT, D. M.; KADER, A. A. Controlled atmosphere-induced changes in $\mathrm{pH}$ and organic acid metabolism may affect color of stored strawberry fruit. Postharvest Biology and Technology, Amsterdam, n. 17, p. 19-32, 1999.

INSTITUTO DE TECNOLOGIA DOS ALIMENTOS. Conservação do morango: relatório Final. Campinas, 1978.

KADER, A. A. Summary of CA requirements and recommendations for fruits other than apples and pears. In: INTERNATIONAL CONTROLLED ATMOSPHERE RESEARCH CONFERENCE, 3., 1997, Davis. Proceedings... Davis: University of California, 1997. p. 1-34. 263 p.

KAWADA, K.; KITAGAWA, H. $\mathrm{CO}_{2}$ atmospheres for the shipment and storage of strawberries. In: SIXTH INTERNATIONAL CONTROLLED ATMOSPHERE RESEARCH CONFERENCE, 1., 1993, New York. Proceedings... New York: NRAES-71, 1993. p. 322. 
KE, D. Y.; GOLDSTEIN, L.; MAHONI, M.; KADER, A. A. Effects of short term exposure to low $\mathrm{O}_{2}$ and high $\mathrm{CO}_{2}$ atmospheres on quality attributes of strawberries. Journal of Food Science, Chicago, v. 1, n. 56, p. 50-54, 1991.

KE, D.; EL-SHEIKH, T.; MATEOS, M.; KADER, A. A. Anaerobic metabolism of strawberries under elevated $\mathrm{CO}_{2}$ and reduced $\mathrm{O}_{2}$ atmospheres. Acta Horticulturae, Leuven, n. 343, p. 93-99, 1993.

LARSEN, M. Flavor changes in strawberries packed in modified atmospheres. Acta Horticulturae, Leuven, n. 368, p. 78-82, 1994.

LARSEN, M.; WATKINS, C. B. Firmness and concentrations of acetaldehyde, ethyl acetate and ethanol in strawberries stored in controlled and modified atmospheres. Postharvest Biology and Technology, Amsterdam, v. 5, n. 1/2, p. 39-50, 1995.

MUÑOZ-DELGADO, J. A. Conservación por el frio de productos perecederos. Revista de Agroquímica y Technologia de Alimentos, Valencia, v. 22, n. 3, p. 30523,1982 .

OLIVEIRA, A. C. de; BILHALVA, A. B.; KOETZ, P. R. Conservação por refrigeração em câmaras industriais de frutos de quatro cultivares de morango (Fragaria ananassa Dutch.). Agros, Pelotas, v. 2, n. 15, p. 93-102, 1979.

ROSEN, J. C.; KADER, A. A. Postharvest physiology and quality maintenance of sliced pear and strawberry fruits. Journal of Food Science, Chicago, v. 3, n. 54, p. 656-659, 1989.
SHAMAILA, M. M.; POWRIE, W. D.; SKURA, B. J. Sensory evaluation of strawberry fruit stored under modified atmosphere packaging (MAP) by quantitative descriptive analysis. Journal of Food Science, Chicago, v. 5, n. 57, p. 1168-1172, 1992.

SMITH, R. B. Controlled atmosphere storage of Redcoat strawberry fruit. Journal of the American Society for Horticultural Science, Alexandria, v. 2, n. 117, p. 260-264, 1992.

SMITH, R. B.; SKOG, L. J. Postharvest carbon dioxide treatment enhances firmness of several cultivars of strawberry. HortScience, Alexandria, v. 27, n. 5, p. 420-421, 1992.

ULRICH, R. Organic acids. In: HULME, A. C. (Ed.). The biochemistry of fruits and their products. New York: Academic, 1970. p. 89-118

WATKINS, C. B.; ZHANG, J. Metabolic responses of fruit to carbon dioxide. Acta Horticulturae, Leuven, n. 464, p. 345-350, 1998.

WELLS, J. M.; COTA, M. Germination and growth of five fungi in low-oxygen and high-carbon dioxide atmospheres. Phytopathology, Saint Paul, v. 60, p. 5053,1970 .

ZHANG, J. J.; WATKINS, C. B. Molecular responses of strawberry fruit to carbon dioxide. In: INTERNATIONAL CONTROLLED ATMOSPHERE RESEARCH CONFERENCE, 3., 1997, Davis. Proceedings... Davis: [s.n.], 1997. p. 35. 